\title{
Web 2.0: New Challenges for the Study of E-Democracy in an Era of Informational Exuberance
}

\section{ANDREW CHADWICK*}

\begin{abstract}
This paper seeks to broaden the debate about edemocracy. Since the emergence of the e-democracy movement, most projects and analyses have used rich and sustained deliberation on an often-romanticized "Athenian" or "public sphere" model as a yardstick to both judge and empirically measure outcomes. This approach, heavily influenced by an ideal of rational critical discourse, has proved notoriously difficult to embed in political organizations. As a consequence, the use of digital network technologies to shape public policy is generally met with incredulity by most politicians, public servants, and citizens. Following a brief critique of the assumptions underlying the literature to date, this paper sketches out an alternative approach-one based on the incentive structures that seem to shape how public servants and citizens now behave online. The approach is derived from preliminary observations of the low threshold co-production behavior characteristic of what has come to be known as "web 2.0." While it may not live up to the high ideals of the deliberative public sphere,
\end{abstract}

\footnotetext{
' Head of Department, Politics and International Relations, and Founding Director, New Political Communication Unit, Royal Holloway, University of London:

http://newpolcom.rhul.ac.uk. I am extremely grateful to the following: Vincent Price and Oren Perez for their helpful comments and suggestions on an earlier version of this paper; Nick Anstead for his careful research assistance; the Moritz College of Law and the Mershon Center for National Security Studies at The Ohio State University for their financial support. This article is an output of the International Working Group on Online Consultation and Public Policymaking, an initiative of the National Science Foundation's Digital Government Program's project Building and Sustaining an International Digital Government Research Community of Practice (Award Number 0540069). Any errors or shortcomings are, of course, my own.
} 
some of this behavior has real value in online consultation and public policymaking. We should acknowledge that successful e-democracy programs may require a plurality of different sociotechnical values and mechanisms.

KEYWORDS: Internet, politics, e-democracy, e-governance, web 2.0, civic engagement, granularity, deliberative democracy, co-production, information, networks. 


\section{INTRODUCTION}

Being at the margins of the formalized procedures grants improvisers an added element of liberty, and sometimes of play, about the choices of which resources to harness and how. If these approaches look rough compared to neat and tidy formal procedures, they are on the other hand highly situated: they tend to include an added element of ingenuity, experience, and skill belonging to the individual and their community (of practice) rather than to the organizational systems. Finally, they all seem to share the same way of operating: small forces, tiny interventions, and on-the-fly add-ons lead, when performed skillfully and with close attention to the local context, to momentous consequences, unrelated to the speed and scope of the initial intervention. These modes of operation unfold in a dance that always includes the key aspects of localness and time (the "here and now"); modest intervention and large-scale effects; on-thefly appearance but deeply rooted in personal and collective skill and experience. ${ }^{1}$

Claims regarding the Internet's potential to reshape democratic life are now in their late teenage years. Scholarship has proceeded through several waves, from early enthusiasm ${ }^{2}$ to pessimistic reaction, ${ }^{3}$ and to the recent, more balanced and empirically driven

1 Claudio Ciborra, The Labyrinths of Information (Oxford: Oxford University Press, 2002), 48.

2 Anthony Corrado, "Elections in Cyberspace: Prospects and Problems," in Elections in Cyberspace: Toward a New Era in American Politics, ed. Anthony Corrado and Charles M. Firestone. (Washington, D.C.: Aspen Institute, 1996); Lincoln Dahlberg, "The Internet and Democratic Discourse: Exploring the Prospects of Online Deliberative Forums Extending the Public Sphere," Information Communication and Society 4, no. 1 (2001): 615-33; Dick Morris, Vote.com: How Big-Money Lobbyists and the Media are Losing Their Influence, and the Internet is Giving Power Back to the People (Los Angeles: Renaissance Books, 1999).

${ }^{3}$ For example, Kevin A. Hill, and John E. Hughes, Cyberpolitics: Citizen Activism in the Age of the Internet (New York: Rowman and Littlefield, 1998); Michael Margolis and David Resnick, Politics as Usual: The Cyberspace "Revolution" (London: Sage, 2000); Anthony G. Wilhelm, Democracy in the Digital Age: Challenges to Political Life in Cyberspace (New York: Routledge, 2000). 
approaches of the post-dotcom era. 4 Despite the increasing maturity of e-democracy scholarship, one inescapable fact remains: the reality of online deliberation, whether judged in terms of its quantity, its quality, or its impact on political behavior and policy outcomes, is far removed from the ideals set out in the early to mid-199os.

This paper seeks to broaden the debate about e-democracy. Since the emergence of the e-democracy movement, most projects and analyses have used rich and sustained deliberation on an oftenromanticized Athenian or public sphere model as a yardstick to both judge and empirically measure outcomes. This approach, heavily influenced by an ideal of rational critical discourse, has proved notoriously difficult to embed in political organizations. As a consequence, the use of digital network technologies to shape public policy is generally met with incredulity by most politicians, public servants and citizens. Following a brief critique of the assumptions underlying the literature to date, this paper sketches out an alternative approach-one based on the incentive structures that seem to shape how public servants and citizens now behave online. The approach is derived from preliminary observations of the low threshold coproduction behavior characteristic of what has come to be known as web 2.o. While it may not live up to the high ideals of the deliberative public sphere, some of this behavior has real value in online consultation and public policy making. We should acknowledge that successful e-democracy programs may require a plurality of different sociotechnical values and mechanisms.

\section{THE DELIBERATIVE ASSUMPTION}

The push for Internet-enabled e-democracy emerged in the early to mid-1990s, as Internet diffusion began to take off in the developed world. It is less often mentioned that the movement is situated in the broader context of the revival of participatory democracy that took place during the 1960 s and 1970s. 5 Inspired in part by oppositional social movements as well as a reappraisal of the direct democracy of Rousseau, political theorists, notably Barber, Macpherson, Pateman,

\footnotetext{
4 For example, Vincent Price, "Citizens Deliberating Online: Theory and Some Evidence," in Online Deliberation: Design, Research, and Practice, ed. Todd Davies (Chicago: University of Chicago Press); Peter M. Shane, Democracy Online: The Prospects for Political Renewal through the Internet (New York: Routledge, 2004).
}

5 Andrew Chadwick, Internet Politics: States, Citizens, and New Communication Technologies (New York: Oxford University Press, 2006), 84-89. 
and Habermas, established a new agenda that has persisted well into the twenty-first century. ${ }^{6}$

At the same time, some empirical political scientists, most notably Fishkin, contributed to the deliberative turn by advocating new forms of opinion polling which rest upon discussion. Echoing themes in Barber's model of "strong democracy," 7 Fishkin suggested that "deliberative polling" has an educative effect; it forces citizens to reconsider preconceived opinions, and is thus superior to the individualist methodology that dominates traditional opinion polling. ${ }^{8}$

For participatory democrats, political deliberation, if-and it is a big "if"-it fulfills certain criteria, can have a transformational influence on citizens. Contrary to liberal individualist perspectives that assume that citizens' political views are pre-determined by their interests, deliberative democrats argue that we discover legitimate solutions to political problems only by engaging in sustained, reflective discourse.

Perhaps the most influential approach to the role of communication in citizen engagement over the last several decades is Habermas's concept of the "public sphere." 9 Habermas argued that the development of early modern capitalism during the eighteenth century heralded a new era of communication based around a culture of enlightened, critical, and reasoned public debate. This culture, while restricted to the propertied, was based upon an independent, privately-owned press, the reading of political periodicals, and rich political discussion in physical spaces such as coffee houses, salons, and pubs. It encouraged critical and reasoned forms of political deliberation to move away from direct political control and allowed public opinion to develop. ${ }^{10}$ Most scholars have deserted Habermas's

\footnotetext{
${ }^{6}$ Benjamin Barber, Strong Democracy: Participatory Politics for a New Age (Berkeley, CA: University of California Press, 1984); Jürgen Habermas, The Structural Transformation of the Public Sphere (Cambridge, MA: MIT Press, 1989); Crawford B. Macpherson, The Life and Times of Liberal Democracy (Oxford: Oxford University Press, 1977); Carole Pateman, Participation and Democratic Theory (Cambridge: Cambridge University Press, 1970).

7 Barber, Strong Democracy (see n. 6).

8 James S. Fishkin, Democracy and Deliberation: New Directions for Democratic Reform (New Haven, CT: Yale University Press, 1991), 2.

9 Jürgen Habermas, The Structural Transformation of the Public Sphere (Cambridge, MA: MIT Press, 1989).

${ }^{10}$ Ibid., 27.
} 
empirical claims and instead use the public sphere as a normative ideal to judge the existing communication structures of contemporary societies. Often this approach involves bringing in concepts from Habermas's more general theories of discourse and deliberation, in attempts to provide criteria for rational-critical discourse. ${ }^{11}$

The ideal of the deliberative public sphere is probably the most influential concept in the scholarly writing on e-democracy. ${ }^{12}$ The Internet emerges as a communication medium uniquely suited to providing arenas for public debates that are relatively spontaneous, flexible, and self-governed. ${ }^{13}$ Citizens that have progressively shrunk into their respective private spheres as the historical public sphere collapsed are, in the Habermasian interpretation, once again able to emerge as a public force.

There are many potential examples of how these normative assumptions underpin both practice and interpretation, but by way of illustration, consider the work of three scholars: Lincoln Dahlberg, Michael Froomkin and Stuart Shulman. Dahlberg extracts six main conditions that e-democracy must fulfill if it is to genuinely create a deliberative public sphere: autonomy from state and economic power; reason rather than assertion; reflexivity; ideal role taking; sincerity; and discursive inclusion and equality. ${ }^{14}$ Froomkin suggests that "New technology may enhance the quantity and especially the quality of mass participation in a representative democracy . . . [I]nternet tools may enrich political debate [and] improve the quality and deliberativeness of both geographic communities and communities of

\footnotetext{
${ }^{11}$ For example, Simone Chambers, Reasonable Democracy: Jürgen Habermas and the Politics of Discourse (Ithaca, NY: Cornell University Press, 1996); James Curran, "Mass Media and Democracy: A Reappraisal." in Mass Media and Society, ed. James Curran and Michael Gurevitch (London: Hodder Arnold, 1991), 82-117; Dahlberg, "The Internet and Democratic Discourse," 615-33 (see n. 2); John S. Dryzek, Discursive Democracy: Politics, Policy, and Political Science (New York: Cambridge University Press, 1990); Lewis A. Friedland, "Communication, Community, and Democracy: Toward a Theory of the Communicatively Integrated Community," Communication Research 28, no. 4 (2001): 358-91.
}

${ }^{12}$ Chadwick, Internet Politics, 83-113 (see n. 5); Zizi Papacharissi, "The Virtual Sphere: The Net as a Public Sphere," New Media and Society 4, no. 1 (2002): 5-23.

13 Peter Dahlgren, "The Internet and the Democratization of Civic Culture," Political Communication 17, no. 4 (2000): 335-40.

24 Lincoln Dahlberg, "The Internet and Democratic Discourse,"615-33 (see n. 2). 
practice." ${ }^{15}$ Finally, Shulman, a scholar of e-rulemaking, is highly critical of the role of interest organizations in supplying web forms and email templates that enable citizens to lobby government agencies. His empirical investigations are framed in such a way that he sees no "signs of deliberation ...., inclusion of difference, respect for a variety of positions, transformation of preferences, as well as expanding and authentic discourse ... [that moves] the process to a higher deliberative plane." 16

Romanticized ideals of deliberative democracy and "thick" citizenship underlay most of the e-democracy literature, whether critical or not. ${ }^{17}$ These are rarely stated, but they are important because they value certain types of activity over others, even though recent-and in my view significant-developments in online political behavior may have very little to do with these ideals.

I share the concerns over the future of civic engagement, and it is indisputable that we should continue to strive for more deliberative forms of political communication. But we should not lose sight of the many other forms of behavior that less easily fit with the deliberative assumption. The 1990 s e-democracy paradigm was preoccupied with the creation of deliberative spaces, particularly discussion forums. It was assumed that they would provide for rich, critical, self-reflective, tolerant, and sustained citizen engagement, elegantly expressed through the medium of the written word. They would allow citizens to deliberate free from the constraints of time and space and would provide additions to traditional policy-making structures. They would be autonomous, self-governing, flexible, unconstrained and selfconsciously designed not to limit or narrowly channel citizen expression. Overall, these criteria and expectations were, as Vedel writes in a classic piece of understatement, "very demanding."18 Given the particular models of citizen behavior privileged in these

\footnotetext{
15 A. Michael Froomkin, "Technologies for Democracy" in Democracy Online: The Prospects for Political Renewal through the Internet, ed. Peter Shane (New York: Routledge, 2004): 3-20; see also A. Michael Froomkin, “Habermas@Discourse.net: Toward a Critical Theory of Cyberspace," Harvard Law Review 116, no. 3 (2003): 749873.

${ }^{16}$ Stuart Shulman, "Whither Deliberation? Mass E-Mail Campaigns and U.S. Regulatory Rulemaking," Journal of E-Government 3, no. 3 (2006): 44-45.

${ }_{17}$ Chadwick, Internet Politics, 83-113 (see n. 5); Damian Tambini, "New Media and Democracy: The Civic Networking Movement," New Media and Society 1, no. 3 (1999): 29.

18 Thierry Vedel, "The Idea of Electronic Democracy: Origins, Visions and Questions," Parliamentary Affairs 59, no. 2 (2006): 232.
} 
approaches, we should not be surprised that e-democracy so often has failed to live up to expectations. And, somewhat ironically, I would like to suggest that several of these values can now be located, in interesting and diverse combinations, in many of the sociotechnical environments of web 2.0.

\section{ASSUMPTION MEETS REALITIES}

The deliberative assumption would not be so damaging had it not so powerfully shaped governments' largely negative responses to edemocracy. The empirical evidence we do have about internet deliberative forums reveals a familiar set of themes that any researcher working in the field will instantly recognize.

First, there is the basic factual point that, to my knowledge, in the majority of online policy-oriented consultations to date only very small groups of citizens have chosen to participate. As an illustration, in the UK, the Hansard Society and the Ministry of Justice's Digital Dialogues program, running from 2006 to 2008, includes several online deliberative forums (alongside blogs, webchats, expert panels, and online questionnaires). Participation rates in the forums have been low. 19

Second, there is a marked reluctance on the part of elected officials and public sector bureaucrats to enshrine deliberative online consultation into their routine modes of operation. This has been attributed to a range of factors including: lack of time and financial resources due to the need to moderate online forums; fear of litigation; intra- and inter-bureaucratic rivalries that pit government agencies and departments against each other; concerns about marginalizing elected legislators and established interest organizations; criticisms of the lack of careful reflection on the design of online environments, specifically how they may undermine deliberation by reducing interactivity; a generalized fear of losing control over the policy agenda and opening up the floodgates by raising citizens' expectations about policy influence; concerns about journalists seizing upon citizen comments and quoting them out of context as a means of framing stories in the mainstream media; concern over the representativeness and expertise of forum participants, especially where small numbers are involved; and finally, concern over the digital divide shaping citizen participation, not just in the sense of physical access to the Internet, but also "media" or

19 See Table 1. 
"electronic" illiteracy weighing heavily on top of more traditional stratifiers of political engagement, such as education, socioeconomic status, age, race and ethnicity. ${ }^{20}$

Table 1: Forum Participation Rates in the UK Digital Dialogues E-Democracy Program, August 2006-August 2007

\begin{tabular}{|l|c|c|}
\hline \multicolumn{1}{|c|}{ Forum } & $\begin{array}{c}\text { Duration } \\
\text { (months) }\end{array}$ & $\begin{array}{c}\text { Number of } \\
\text { citizen posts }\end{array}$ \\
\hline $\begin{array}{l}\text { Department of Communities and Local } \\
\text { Government Forum }\end{array}$ & 6 & 411 \\
\hline $\begin{array}{l}\text { Department for Constitutional Affairs } \\
\text { Family Justice Division Forum }\end{array}$ & 3.5 & 172 \\
\hline $\begin{array}{l}\text { Department for Constitutional Affairs } \\
\text { Family Justice Division Forum } \\
\text { (Children and Young People) }\end{array}$ & 2 & 26 \\
\hline $\begin{array}{l}\text { The Review of the Funding of Political } \\
\text { Parties Forum }\end{array}$ & 2.5 & 217 \\
\hline $\begin{array}{l}\text { Foreign and Commonwealth Office } \\
\text { European Youth Parliament Forum }\end{array}$ & 1.5 & 57 \\
\hline Planning Portal Forum & 4 & 67 \\
\hline $\begin{array}{l}\text { Law Commission Tenth Programme of Law } \\
\text { Reform Forum }\end{array}$ & 1.75 & 43 \\
\hline
\end{tabular}

Source: Hansard Society (2007)

Of course this is not the whole story. There are examples of edemocracy that have proven extremely valuable for citizens and

\footnotetext{
20 See for example, Stephen Coleman, "Connecting Parliament to the Public via the Internet," Information, Communication and Society 7 (2004): 1-22; Jane E. Fountain, Building the Virtual State: Information Technology and Institutional Change (Washington, D.C.: Brookings Institution Press, 2001); Helen Margetts, and Patrick Dunleavy, Cultural Barriers to E-Government (London: National Audit Office, 2002), http://www.governmentontheweb.org/downloads/papers/Cultural_Barriers.pdf.; Karen Mossberger, Caroline J. Tolbert, and Ramona S. McNeal, Digital Citizenship: The Internet, Society, and Participation (Cambridge, MA: MIT Press, 2008); Jennifer Stromer-Galley, "Online Interaction and Why Candidates Avoid It," Journal of Communication 50 (2000):111-32.
} 
government. There are no means of producing a definitive balance sheet at this point, but I would estimate that these examples are in the minority, and more fundamentally, that their value was not necessarily derived from their deliberative nature. Probably the largest and most rigorous empirical study of online deliberation to date-Price and Capella's Electronic Dialogue and Healthcare Dialogue experiments-were broadly successful, but they were "not intended to be formally deliberative exercises; instead, group members were simply invited to discuss a number of topics." ${ }^{21}$ And in these cases, the discussions were probably not inclusive enough to satisfy the deliberative assumption. "Argument repertoire" best predicted participation in online discussion. This measure of political sophistication-based on the number of different arguments citizens were able to use in support of their opinions-was strongly correlated with age and education. Older and more highly educated individuals were significantly more likely to participate than others. The quantity of contributions increased as levels of political knowledge and educational attainment increased. While we need to recognize that these experiments did lead to interactive discussion and an increase in political knowledge among participants, these were not classical deliberative encounters.

The characteristics that shape the success or failure of $e$ democracy are manifold and complex, and there is insufficient space to discuss them here. Scholars ought to be interested, however, in why programs succeed and why they fail, and I would like to suggest that this has something to do with unrealistic assumptions about the incentives that shape political behavior in the online environment. Let me be clear about my aim. First, I do not seek to echo the argument that the online environment's disinhibiting effects or the absence of informal or formal sanctions for those seeking to undermine debate render it a poor relation of face-to-face discussion. Again, this is empirically contested: for every criticism of the online environment there is a counterpoint about its capacity to reduce constraints on the voices of the less powerful, not to mention the many concerns about the quality of traditional face-to-face political interaction. Second, and more fundamentally, I am not seeking to fortify the generalization that citizens lack the motivation to think about and discuss politics. ${ }^{22}$

\footnotetext{
${ }^{21}$ Vincent Price, "Citizens Deliberating Online," 9 (see n. 4); Vincent Price, and Joseph N. Cappella, "Online Deliberation and its Influence: The Electronic Dialogue Project in Campaign 2000," IT and Society 1, no. 1 (2002): 303-29.
}

22 Vedel, "The Idea of Electronic Democracy," 232 (see n. 18). 
Not only are these points empirically disputed, ${ }^{23}$ it is also unnecessary to assume that citizens are highly informed and highly motivated. Most citizens will fall into categories along a continuum, and it is highly unlikely that they will remain in one category in perpetuity. Most of us occupy positions between these two extremes, depending upon our contexts. It is my hypothesis that sociotechnical environments that have this level of granularity "designed in"-to allow citizens to demonstrate citizenship in diverse ways-are more likely to be successful than those that do not.

\section{Politics: WeB 2.0}

Before attempting to understand what web 2.0 offers for edemocracy, we need some way of defining it and of teasing out its broader implications for political behavior in a way that stays close to its technological characteristics without reducing it to those characteristics. Space limits preclude a full discussion, but here I build upon Tim O'Reilly's seminal outline, arguably the most influential discussion of the term web 2.0 to date. ${ }^{24}$ O'Reilly's technology-centered approach defines web 2.0 in terms of seven key themes. Some of these are more relevant to my purposes than others and some require extra theoretical work to render them meaningful for this discussion. ${ }^{25}$ Nevertheless, the seven principles are: the Internet as a platform for political discourse; the collective intelligence emergent from political web use; the importance of data over particular software and hardware applications; perpetual experimentalism in the public domain; the creation of small scale forms of political engagement through consumerism; the propagation of political content over multiple applications; and rich user experiences on political websites.

23 Michael X. Delli Carpini, Fay Lomax Cook, and Lawrence Jacobs, "Public Deliberation, Discursive Participation, and Citizen Engagement: A Review of the Empirical Literature," Annual Review of Political Science 7 (2004): 315-44.

${ }^{24}$ This section draws in part upon Andrew Chadwick, and Philip N. Howard, "Introduction: New Directions in Internet Politics Research," in The Handbook of Internet Politics, ed. Andrew Chadwick and Philip N. Howard (New York: Routledge, 2008).

${ }^{25}$ Tim O'Reilly's original principles are: "The Web as Platform"; “Harnessing Collective Intelligence"; "Data is the Next Intel Inside"; "The End of the Software Release Cycle"; "Lightweight Programming Models"; "Software Above the Level of a Single Device"; and "Rich User Experiences." See Tim O'Reilly, "What Is Web 2.o?: Design Patterns and Business Models for the Next Generation of Software," 2005, http://www.oreilly.com/lpt/a/6228. 


\section{A. The InTERnet as a Platform for Political Discourse}

In essence, this principle means that the web has moved from the older model of static pages toward a means of enabling a wide range of goals to be achieved through networked software services. The archetypal web 2.0 web-as-platform service is Google, whose value depends almost entirely on the interface of its distributed advertising network, its search algorithm, and its huge database of crawled pages. Two key features of this aspect of web 2.0 are particularly salient: first, the power of easily scalable networks and second, the "long tail."

Easily scalable networking involves an organization being able to flexibly adapt to sudden growth surges and ad hoc events that increase demand for its services. The theory of the long tail ${ }^{26}$ is that online distribution is changing the political economy of content creation as online storage and distribution significantly reduce the costs and increase the market for diverse content. This results in a sales/products curve with a "head" of mass market products and a long "tail" of niche products. The Internet thus contributes to a more diverse and pluralistic media landscape.

These web-as-platform principles can be seen at work in a range of political arenas. The 2004 primary and presidential campaigns in the United States saw the emergence of a campaigning model based on online venues loosely meshed together through automated linking technologies, particularly blogs. ${ }^{27}$ However, nowhere is the idea more strongly embodied than in the recent shift towards online social networking on platforms such as Facebook and MySpace, and social media sites such as YouTube. The symbolic moment came in January 2007 when John Edwards and Barack Obama announced their candidacies for the Democratic presidential nomination via brief and informal video postings on YouTube. The U.S. midterms of November 2006 had already witnessed an explosion of political activity on social networking sites, as well as the intensification of blogging by candidates and a long tail of amateur pundits. ${ }^{28}$

${ }^{26}$ Chris Anderson, The Long Tail: How Endless Choice is Creating Unlimited Demand (London: Random House, 2006).

27 Andrew Chadwick, "Digital Network Repertoires and Organizational Hybridity," Political Communication 24, no. 3 (2007): 283-301; Matthew Hindman, "The Real Lessons of Howard Dean: Reflections on the First Digital Campaign," Perspectives on Politics 3, no. 1 (2005): 121-28.

${ }^{28}$ Christine B. Williams, and Jeff Gulati, "Social Networks in Political Campaigns: Facebook and the 2006 Midterm Elections" (Paper read at Annual Meeting of the American Political Science Association, Chicago, IL, 2007). 


\section{B. Collective InTELligenCE}

The second theme of web 2.0 is collective intelligence. The core idea is that a distributed network of creators and contributors, the majority of them amateurs, can, using simple online tools, produce information goods that may outperform those produced by so-called authoritative, concentrated sources. Examples of this abound, but two stand out as having caught the political imagination: free and open source software projects and user generated content sites. The underlying model of online collaboration that produces these vast collections of human intelligence has been much debated. Opinions differ, for instance, over the extent to which hierarchy matters in these environments. Some, such as Weber, suggest that it accounts for a great deal, 29 while others, such as Weinberger, downplay its importance. $3^{\circ}$ These debates aside, it seems safe to suggest that web 2.0 rests in part upon a broadly voluntarist model of knowledge creation.

At a basic level, many of the interesting and significant developments in online collective action have been enabled by free and open source software creations, providing a good example of elective affinity between political values and technological tools. Wikipedia itself has become a political battleground, as supporters of candidates, causes, groups, movements, and even regimes, engage in incessant microscopic "edit wars" over entries. Beyond this, the principle of collective intelligence now animates politics in a variety of arenas. The blogosphere has enabled ongoing citizen vigilance on a grand scale. Political actors and media elites now exist in an always-on environment in which it is impossible to escape the "little brother" surveillant gaze of citizen-reporters, from easily-assembled Flickr photostreams of marches and demonstrations ignored by mainstream media, to video bloggers such as Connecticut Bob, who took to the streets with his home movie camera to track Senator Joseph Lieberman's less guarded moments during the 2006 U.S. midterms. ${ }^{31}$

\footnotetext{
${ }^{29}$ Steven Weber, The Success of Open Source (Cambridge, MA: Harvard University Press, 2004).

30 David Weinberger, Everything is Miscellaneous: The Power of the New Digital Disorder (New York: Henry Holt and Company, 2007).

${ }^{31}$ See "Connecticut Bob," http://ctbob.blogspot.com (accessed October 14, 2008).
} 


\section{THE IMPORTANCE OF DATA}

The third principle of web 2.0 is the importance of data. The central claim is that the current era is characterized by the aggregation of huge amounts of information: those who can successfully mine, refine, and subsequently protect it are likely to emerge as dominant. Most of these data have been created from the concentrated labor of volunteers or they may simply be the by-products of countless distributed and coincidental interactions. The key point, however, is that informational value emerges from the confluence of distributed user generated content and its centralized exploitation.

This principle points to the ongoing importance of long-standing controversies surrounding privacy, surveillance, and the commercial and political use of personal information..$^{22}$ The ease of connection in the social networking environments of web 2.0 offers a multitude of possibilities for automated gathering, sorting, and targeting. In the early days of the web, political actors would often complain that they had "no control" over the online environment or that they did not know how to target particular groups or supporters. 33 The applications of web 2.0 render these tasks much more manageable, as individuals willingly produce and reveal the most elaborate information about their tastes and preferences within enclosed technological frameworks. In the realm of political campaigns, egovernment, and e-democracy, social networking sites thus offer political actors many advantages over the open web.

\section{PERPETUAL EXPERIMENTALISM IN THE Public DOMAIN}

The fourth theme is perpetual experimentalism in the public domain. As indicated above, the attraction of O'Reilly's model is that it captures literal, quite narrow developments in technological practice; but the model can also be used at a metaphorical level to capture social and political behavior. Web 2.0 applications have been characterized by an unusual amount of public experimentalism. This is most obviously illustrated by the "perpetually beta" status of many of the popular services (for example Flickr, which stayed beta even after being acquired by Yahoo). While this is a symptom of the requirements of building and testing scalable web applications on

\footnotetext{
$3^{2}$ Philip N. Howard, New Media Campaigns and the Managed Citizen (Cambridge: Cambridge University Press, 2006).

33 Stromer-Galley, "Online Interaction," 111-32 (see n. 20).
} 
meager resources, it also reflects a value shift away from tightly managed development environments and towards those characterized by fluidity and greater collaboration between developers and users.

This sense of democratic experimentalism has of course been one of the driving values of the Internet since its earliest days, ${ }^{34}$ and I have argued elsewhere that this principle should be at the centre of the development of e-government systems because it encourages participation by democratically conscious software engineers. ${ }^{35}$ But web 2.0 has seen democratic experimentalism proliferate across a surprising range of political activities. Election campaigns in the United States are now characterized by obsessive and continuous recalibration in response to instant online polls, fundraising drives, comments lists on YouTube video pages, and blog posts. But there is perhaps no better example of the impact of the permanent beta in politics than the British prime minister's e-petitions initiative, "launched" in November 2006. At the time of writing, the site remains in beta-and will probably do so for some time-until it metamorphoses into another application, or is abandoned. Adding the beta stamp to an e-government initiative at the heart of the executive machinery of one of the world's oldest liberal democracies illustrates just how far these values and working practices have penetrated.

\section{E. The Creation of SMall Scale Forms of Political ENGAGEMENT THROUGH CONSUMERISM AND THE PROPAGATION OF POLITICAL CONTENT ACROSS MULTIPLE APPLICATIONS}

The next two web 2.o themes-the creation of small scale forms of political engagement through consumerism and the propagation of political content across multiple applications-are more specialized, but still reveal important aspects of the new politics. Many data cannot be sealed off from public use because it would be politically unacceptable; or a business model might depend upon open access. Web 2.0 is characterized by the mashing together of different data in pursuit of goals that differ from those originally intended by the producers of those data. This practice may grant increased power to citizens. For example, British activist volunteer group mySociety has launched a number of sites, such as TheyWorkForYou and

34 Chadwick, Internet Politics, 38-48 (see n. 5).

35 Andrew Chadwick, "Bringing E-Democracy Back In: Why it Matters for Future Research on E-Governance," Social Science Computer Review 21, no. 4 (2003): 443-55. 
FixMyStreet that combine publicly accessible government data with user generated input. ${ }^{36}$ TheyRule allows users to expose the social ties among political and economic elites by mapping out the network structures of the corporate boards of multinational firms. 37 Meanwhile, mobile Internet devices are increasingly important, again with a distinct user generated inflection through practices such as video and photoblogging, as well as mainstream news organizations' increasing reliance on amateur "witness reporters." 38

\section{F. RICH USER EXPERIENCES ON POLITICAL WEBSITES}

The final theme of web 2.0 is rich user experiences on political websites. In the narrow technical sense, this refers to the development of applications designed to run code (specifically asynchronous javascript and $\mathrm{xml}$, or AJAX) inside a web browser in ways that facilitate interactivity and the rapid retrieval, alteration, and storage of data. Most of the successful web 2.0 applications combine such capabilities with back-end databases that store user generated content able to be modified by others. While valuable information is created by such actions, these are often not the result of heroic individual efforts, but of aggregated small-scale, low-threshold forms of behavior: seemingly "happy accident" outcomes of thousands of individual interactions. ${ }^{39}$ These are not entirely accidental, however, as many web 2.0 systems are deliberately designed to capture useful aggregated data from even the most minimal of user activities. This occurs on sites that encourage users to create original content but which also offer readers the chance to edit it or rate it. For example, highly-rated pieces rise to the top of the recommended diaries feature

\footnotetext{
${ }^{36}$ See "MySociety," http://www.mysociety.org; "TheyWorkForYou.com," http://www.theyworkforyou.com; "FixMyStreet," http://www.fixmystreet.com (accessed October 14, 2008).

37 See "They Rule," http://www.theyrule.net/html/ (accessed February 14, 2009).

${ }^{38}$ James Stanyer, "Web 2.0 and the Transformation of News and Journalism" in The Handbook of Internet Politics, ed. Andrew Chadwick and Philip N. Howard. (New York: Routledge, 2008): 203.

39 Bruce Bimber, Andrew J. Flanagin, and Cynthia Stohl, "Reconceptualizing Collective Action in the Contemporary Media Environment," Communication Theory 15, no. 4 (2005): 372; Andrew Chadwick, "Digital Network Repertoires and Organizational Hybridity," Political Communication 24, no. 3 (2007): 290.
} 
on the Daily Kos home page while MoveOn's Action Forum contains a similar mechanism for prioritizing issues. $4^{\circ}$

Perhaps the most significant aspect of web 2.0 politics as rich user experience has emerged in the form of online video. This took most commentators by surprise. Past predictions of media convergence generally argued that an abundance of bandwidth would make the Internet a more televisual, large screen experience. YouTube may eventually metamorphose into a fully converged large-screen online broadcasting network, but the indications so far are that it will not, primarily because it has generated a huge user base that savors its small-screen, do-it-yourself format.

In the political sphere, YouTube has made a sizeable dent in earlier predictions of the emergence of slick, professionalized televisual political communication able only to be resourced by government and wealthy politicians. ${ }^{41}$ This is clearly wide of the mark when both political elites and citizens perceive that the visual genres of an effective YouTube video do not depend upon professional media production techniques. The cynical may decry the rise of YouTube campaigning on the grounds that it is inauthentic "spin" based on manufactured folksy imagery. In the United Kingdom, the Conservative Party leader David Cameron was widely criticized by the mainstream media for this approach on his site, Webcameron, launched in 2006.42 And yet the impressionistic evidence suggests that the method attracts members of the public, evidenced by more than 30,000 citizen postings during his forum's experimental lifespan between May and December 2007.43 In important ways, each new digital technology that captures public attention quickly becomes politicized. YouTube has evolved into one of the most popular online applications, thereby becoming a valuable tool for content distribution by politicians.

\footnotetext{
40 See Markos Moulitsas Zúniga, "Daily Kos: State of the Nation," http://www.dailykos.com (accessed October 14, 2008); and MoveOn.org, "ActionForum," http://www.actionforum.com (accessed October 14, 2008).

${ }^{41}$ Michael Margolis, and David Resnick, Politics as Usual: The Cyberspace "Revolution" (London: Sage, 2000).

42 See for example, Matthew Tempest. "'Yo, my name's Dave, yeah?' One MP's riposte to Webcameron." The Guardian News blog. 2006, http://www.guardian.co.uk/news/blog/2006/oct/12/notanotherone.
}

43 David Cameron, http://www.webcameron.org (accessed August 27, 2008). 
Technologies possess inherent properties that shape and constrain political norms, rules, and behavior, but these must be situated within political contexts.44 The seven themes of web 2.0 discussed above are by no means exhaustive and only begin to provide analytical purchase on the changes currently underway. Yet it would be a mistake to dismiss web 2.0 as solely the creation of marketing departments. We need to try to make sense of the sometimes remarkable pace of these recent changes, while also recognizing the continuities with the Internet's earlier phases. The area of e-democracy should be no exception.

In the rest of this paper I try to identify what we might seek to learn about the values and incentive structures that seem to characterize political behavior in these environments and the extent to which they may have value for e-democracy. I organize this into two broad sections. First, I approach the problem from what might be termed the demand side-the perspective of citizens. Then, I approach it from the supply side-the perspective of government organizations. 45

\section{LEARNING From Web 2.0: CITIZENS}

What can we learn from citizen behavior in web 2.0 environments?

\section{A. USABILITY}

The leading web 2.0 applications are dominated by a distinctive usability ethos that was often absent from the earlier phases of the web's development. Early critical accounts of Internet-mediated politics often bemoaned the growth of a digital divide between DIY websites and the glitzy, "professionalized" sites of the wealthy and powerful. While it would be a mistake to ignore the powerful backend technologies that enable web 2.0 sites to function, it is obvious that the usability doctrines of figures such as Nielsen ${ }^{46}$ have had a

\footnotetext{
44 Chadwick, Internet Politics 17-21 (see n. 5).

45 For a similar approach see Helen Margetts, "E-Government in Britain: A Decade On," Parliamentary Affairs 59, no. 2 (2006): 250-65; Helen Margetts and Patrick Dunleavy, Cultural Barriers to E-Government (London: National Audit Office, 2002), http://www.governmentontheweb.org/downloads/papers/Cultural_Barriers.pdf.

46 Jakob Nielsen, Designing Web Usability: the Practice of Simplicity (Indianapolis, IN: New Riders, 2000).
} 
major influence on the look and feel of the web 2.0 environment. Accessibility and ease of use are the core principles of extremely simple messaging platforms such as tumblelogs 47 or Twitter. ${ }^{48}$ The UK's mySociety projects are based on the principle of "small is beautiful" and of enabling citizens to do one simple thing easily and elegantly. 49 TheyWorkForYou, for example, provides an intuitive searchable interface to Hansard, the record of all UK Parliamentary proceedings. Debates are listed in an easy to follow format and allow for citizen comments on specific parliamentarians' speeches. Once submitted, citizen comments appear alongside the original parliamentary speech. Citizens are also able to comment on the comments of others. The site also provides citizens with the opportunity to learn about the views and behavior of Members of Parliament, including their voting record, speeches, committee membership, and entries in the register of members' interests..$^{\circ}$ In web 2.0 sociotechnical environments, the complexity often emerges from the aggregation of many simple contributions.

\section{B. THRESHOLDS}

Many web 2.0 services rely upon large numbers of individuals behaving with regularity in low threshold ways. A threshold is here understood to be a function of an individual's calculation about the expected utility of participating in a given activity based on the likelihood of participation by others. ${ }^{11}$ But the key point about low threshold political behavior online is that much of the technological architecture of web 2.0 applications designs in low and high threshold activities and many variants in between. An example is the division of labor typified by many news aggregators and blogs such as Digg, BBC

\footnotetext{
47 See "Tumblr," http://www.tumblr.com (accessed October 14, 2008).

${ }^{8} 8$ See "Twitter," http://www.twitter.com (accessed October 14, 2008).

49 See "MySociety," http://www.mysociety.org (accessed October 14, 2008).

${ }^{50}$ See "TheyWorkForYou.com: Are your MPs and Peers Working for You in the UK's Parliament?," http://www.theyworkforyou.com (accessed October 15, 2008).

51 Mark Granovetter, "Threshold Models of Collective Behavior," American Journal of Sociology 83, no. 6 (1978): 1420-43; John H. Miller and Scott E. Page, "The Standing Ovation Problem," Complexity 9, no. 5 (2004): 8-16;

http://www.econ.iastate.edu/tesfatsi/StandingOvation.MillerPage.pdf (accessed October 10, 2008); Mancur Olson, The Logic of Collective Action: Public Goods and the Theory of Groups (Cambridge, MA: Harvard University Press, 1965), 164.
} 
News Online, or AOL News. $5^{2}$ This user generated content circulates around a reactive, story-telling model. Citizens write stories, and a sample of these is opened up to comments and ratings. Some tell the stories, others make brief comments, and others rate both the story and the comments with a simple button-click. Highly rated stories rise to the top of the list. Many of these stories begin life as stories about other stories-remixed versions of the content of others.

A good policy example comes in the form of "Frank: Your Stories," a user generated element on the UK government's drugs awareness site for young people.53 The page allows users to write and upload their own stories, providing an interesting combination of an information site (with a public health agenda) that is now relying on user content to help it fulfill its role. The popularity of this approach is explained by the fact that it is not an all-or-nothing model. Quantitatively and qualitatively different forms of contribution are facilitated by the technological architecture. Many citizens seem to find mixing together sources of digital content originally created by others to be a compelling and worthwhile experience in its own right. While it would be an exaggeration to say that the political economy of political content creation has been transformed, it seems to have shifted in significant ways.

\section{TRusted Governance}

Trust is one of the most valuable and one of the most elusive forces in online politics. Anonymity and pseudonymity may encourage freedom of expression but they also constantly undermine sustained collaboration in problem solving. Government-run online consultations have been criticized for their insensitivity to how the sociotechnical environment encourages or undermines trust.54 Web 2.o environments do not solve these problems, but in recent years some interesting models have emerged for sustainable co-production,

\footnotetext{
${ }^{2}$ See http://www.digg.com; http://news.bbc.co.uk/1/hi/talking_point/default.stm; and http://news.aol.com (accessed October 10, 2008).

53 See "FRANK- Stories," http://www.talktofrank.com/article.aspx?id=244 (accessed October 15, 2008).

54 Scott Wright, "Government-run Online Discussion Fora: Moderation, Censorship and the Shadow of Control." British Journal of Politics and International Relations 8, no. 4 (2006): 550-68.
} 
reflecting an interesting blend of self-governance and regulation. ${ }^{55}$ Take three examples: Wikipedia, eBay, and Digg. ${ }^{6}$ Wikipedia relies on a blend of spontaneous self-correction by the army of volunteer "Wikipedians" and an expanding conception of hierarchy (entries are now frequently locked down; prominent warnings are increasingly displayed at the top of contentious or incomplete entries). EBay is temporally pre-web 2.0, but its mechanisms for generating sufficient trust for online transactions to occur (low threshold buyer and seller ratings) have provided the inspiration for many web 2.0 projects. Digg, the "editorless" user generated news site, relies on individuals to submit links to interesting stories.57 Submissions are given a simple positive or negative rating by users and rise or fall on this basis. Users may add brief textual comments to substantiate their decision to "digg" or "bury" a story, adding a very low threshold deliberative element.

Policymakers have started to experiment with such mechanisms. In 2007, the New Zealand Police Service was required to draft a submission of the Police Act for renewal. They decided to undertake this process using a wiki, open to all members of the public. The experiment was a success and attracted much international interest. According to information on the project on its (now archived) website, the result of the consultation will shape the final version of the bill, which will be introduced to the New Zealand Parliament..$^{8}$

It would be naive to suggest that co-production environments such as Wikipedia, eBay and Digg create the high levels of trust that are typical of face to face encounters such as deliberative polling. But they do seem to encourage voice and loyalty, while discouraging exit.59 In

\footnotetext{
55 For an overview, see Yochai Benkler, The Wealth of Networks: How Social Production Transforms Markets and Freedom (New Haven, CT: Yale University Press, 2006).

${ }^{6}$ The three examples were discussed in more detail at "Engaging with the 'Google Generation"' (workshop, Oxford Internet Institute, Oxford, England, December 19, 2006); and in William H. Dutton, and M. Peltu, "Reconfiguring Government-Public Engagements: Enhancing the Communicative Power of Citizens" (Oxford Internet Institute, Oxford, England, April 2007), http://people.oii.ox.ac.uk/Dutton/wpcontent/uploads/2007/04/FD9.pdf (accessed October 15, 2008).
}

${ }^{57}$ See "Digg," http://www.digg.com (accessed October 15, 2008).

$5^{8}$ New Zealand Police, “Police Act Review Wiki," Consultation Documents, http://www.policeact.govt.nz/wiki/ (accessed February 14, 2009).

59 Albert O. Hirschman, Exit, Voice, and Loyalty: Responses to Decline in Firms, Organizations, and States (Cambridge, MA: Harvard University Press, 1970). 
this sense, the small scale interactions in these environments offer potentially valuable lessons for online consultation, where ease of exit has long been perceived as a barrier to citizen and government participation.

\section{THIRD PLACES}

Social networking sites such as Facebook ${ }^{60}$ differ in important respects from the open web. They provide areas in which individuals express many different facets of their identities and in which diverse lifestyles and values play out. The affordances of social networking environments encourage us to build our lives online. It has been argued that the Internet is a "purposive" medium and is therefore less likely to have "by-product learning" effects in comparison with other media such as television, where serendipitous encounters with political information occur in the context of entertainment. ${ }^{61}$ For some, this reinforces traditional stratifiers of political engagement. ${ }^{62}$

But while this may have been true of earlier phases of the Internet, the emergence of social networking applications has altered the context. Political life in Facebook "piggybacks" on the everyday life context of the environment, in much the same way as "third places" function in community-building, social capital, and civic engagement away from the home and the workplace. ${ }^{63}$ Politics here aligns itself with broader repertoires of self-expression and lifestyle values. Politics in Facebook goes to where people are, not where we would like them to be. In 2007, when the company opened up its code as a means of encouraging programmers to create extra features, this unleashed a wave of new "applications," the majority concerned with the expression of lifestyle choices and consumerism. Also significant are the growing number of directly political applications (over 500 by February 2008), such as "Causes," which in early 2008 averaged

\footnotetext{
${ }^{60}$ See "Facebook," http://www.facebook.com (accessed October 15, 2008).

61 Markus Prior, Post-Broadcast Democracy: How Media Choice Increases Inequality in Political Involvement and Polarizes Elections (New York: Cambridge University Press, 2007): 27-162. For the original argument see Anthony Downs, An Economic Theory of Democracy (New York: Harper and Row, 1957).
}

62 Bruce Bimber and Richard Davis, Campaigning Online: The Internet in U.S. Elections (New York: Oxford University Press, 2003).

63 Ray Oldenburg, The Great Good Place: Coffee Shops, Bookstores, Bars, Hair Salons, and Other Hangouts at the Heart of a Community (New York: Pargon House, 1997), 16. 
114,000 daily active users. ${ }^{64}$ Many Facebook profile pages are now a mish-mash of content and genres, where music, film, and fashion sit alongside political campaigns, donation drives, sloganeering and so on. And we should not lose sight of the fact that it is, once again, a low-threshold deliberative environment, with features such as "The Wall" and "Groups" allowing users to comment on others' profiles and to hold ongoing conversations in semi-public spaces.

\section{E. THE AFFECTIVE TURN}

Much of the commentary on web 2.0 has focused on the rise of highly individualized forms of online expression and how these may contribute to a broader social narcissism. ${ }^{65}$ Much of the writing about blogs and YouTube, for example, has criticized what are perceived to be self-obsessed, egotistical communication genres. Some lament the rise of audio-visual content online, complaining that it signals the end of an innocent ideal of text-based communication free from the constraints of physical markers such as ethnicity, appearance, accent, and social class. ${ }^{66}$ Many of the early advocates of e-democracy celebrated the egalitarian quality of textual computer-mediated communication. ${ }^{6} 7$

It seems clear that the emergence of visual communication genres online presents challenges to our understanding of e-democracy. But is the news all bad? Over the last decade or so, some have sought to broaden the concerns of social and political theory to encompass the role of affective dimensions in the regulation of social life. Giddens has called for a "democracy of the emotions in everyday life," 68 while Young wrote of political deliberation's "internal" exclusionary

\footnotetext{
64 Facebook Causes Application,

http://www.new.facebook.com/apps/application.php?id=2318966938\&b=\&ref=pd_r_c (accessed October 15, 2008).

65 Andrew Keen, The Cult of the Amateur: How Today's Internet Is Killing Our Culture and Assaulting Our Economy (New York: Doubleday, 2007).
}
${ }^{66}$ Andrew Chadwick, "Web 2.o Politics: Three Things We Should Celebrate, and Three Things We Shouldn't" (Paper read at RSA special conference: "The Social Impact of the Web: Society, Government and the Internet," May 25, 2007).

${ }^{67}$ See for example, Marc A. Smith and Peter Kollock, eds. Communities in Cyberspace (New York: Routledge, 1999).

${ }^{68}$ Anthony Giddens, Runaway World: How Globalization is Reshaping Our Lives (New York: Routledge, 1999), 63. 
dynamics, which subtly devalue informal and emotional discourse. ${ }^{69}$ More recently, Papacharissi,70 drawing upon Inglehart and Welzel,71 has written of a "civically motivated narcissism," based on the view that "self-expression values are connected to the desire to control one's environment, a stronger desire for autonomy, and the need to question authority" and that "self-expression values are not uncivic."72 Citizen-produced audio and video deviate from the ideal of textual deliberative discourse but in the genres of YouTube they arguably democratize political expression by creating a new grassroots outlet for the affective dimensions in politics.

We can see how certain policy sectors might be more attuned to this style of discourse than others. The site of the UK's ongoing National Health Service review, started in summer of 2007, features a Have Your Say section, complete with a news and announcements blog that allows public commenting. The site also incorporates Lord Darzi's personal blog, online surveys for NHS stakeholders and members of the public, and an accompanying YouTube stream. ${ }^{73}$

Though there remains much empirical work to be done in this area, we can hypothesize that many citizens are at ease uploading a quickly recorded video delivered in an informal, conversational style, but less confident if asked to formally deliberate. Thus, while we may be losing the egalitarian effects of text-based computer-mediated communication, it is not at all clear that audiovisual online culture will have entirely negative effects on citizen engagement.

\section{F. NUMBERS}

Finally, there is the basic, often elided, question of numbers. Faced with low participation rates, many e-democracy programs have fallen back on the argument that numbers do not matter and that it is

\footnotetext{
69 Iris M. Young, Inclusion and Democracy (New York: Oxford University Press, 200o), 53-57.

70 Zizi Papacharissi, "The Virtual Sphere 2.o: The Internet, the Public Sphere and Beyond." The Handbook of Internet Politics (New York: Routledge, 2008), 236-39.

${ }^{71}$ Ronald Inglehart and Christian Welzel, Modernization, Cultural Change and Democracy (London: Cambridge University Press, 2005).

72 Ibid., 70.

73 UK National Health Service, "Our NHS, Our Future: Have Your Say Website," http://www.ournhs.nhs.uk (accessed October 15, 2008).
} 
the quality of political deliberation that counts. The most well-known formal deliberative schemes have never grown beyond communities of a few hundred. To briefly revisit a point made earlier in this essay, the reliance by interest organizations on form emails and web templates that enable many thousands of citizens to send comments to policymakers has been heavily criticized. 74

But should we be so quick to devalue large numbers of individual citizen actions, even if those actions carry very little cost? Web 2.0 environments are significant because they enshrine participation by thousands in scalable ways. The most powerful web 2.0 applicationsand this is most obvious for online social networking sites such as Facebook, MySpace or Bebo-derive their value from the predictable network effects associated with large numbers of participants. Political networks in Facebook and MySpace, because they are not tied to a deliberative model, are able to grow comparatively quickly, and the more people participate, the more value there is in the network. The first signs of this dynamic emerged during the 2004 U.S. presidential primaries, when it became obvious that citizens were very willing to add simple one-line comments to blog posts, often in very large quantities. A good example, again, is the Daily Kos blog, which quite frequently receives comments on individual blog posts numbering in the thousands, and there may be several such stories in any given day.

While it has been criticized for its lack of deliberative mechanisms, if judged in terms of the number of participants, the UK Prime Minister's E-Petitions website is one of the most successful edemocracy projects of all time. In its first year, over 29,000 petitions were submitted. Accepted petitions attracted 5.8 million signatures from 3.9 million unique email addresses. 75 E-Petitions have quickly become part of the online repertoire of citizen groups in the UK and have viral characteristics. For example, a search on Facebook reveals a number of groups that have been formed around specific petitions. ${ }^{76}$

\footnotetext{
74 Shulman, "Whither Deliberation?," 41-64 (see n. 16).

75 UK Prime Minister's Office, "E-Petitions Website," http://petitions.number10.gov.uk (accessed October 15, 2008).

${ }^{76}$ Facebook Downing Street E-Petitions, Search, http://www.facebook.com/s.php?q=downing+street+petition\&n=$1 \& \mathrm{k}=200000010$ \&init $=r$ (accessed October 15,2008 ).
} 


\section{LEARNING FROM WEB 2.0: GOVERNMENT}

Finally, I turn to what web 2.0 potentially offers government.

\section{A. MoRe GranUlarity, LESS RisK}

Just as web 2.0 environments lower thresholds for citizens, they also lower them for government. A major disadvantage of the deliberative forum model is its high profile, "one-size-fits-all" approach. Many risk factors present themselves in this environment, but three are particularly salient. First, forum participation rates will be low, over time deterring citizens from entering the forum for fear of "standing out" as well as attracting negative media coverage. Second, the forum descends into irrelevance or flame wars, and becomes heavily censored or an embarrassment. Third, the forum's sponsors lose control of its agenda and either over-moderate it or disown it.

The more granular web 2.0 environments, where different repertoires of engagement sit side-by-side, from postings to comments to ratings to wiki editing and so on, do not eliminate these risks but may reduce them. Consider, for example, the UK Foreign Office's group blog. 77 This features entries by the UK's Foreign Minister, junior ministers, career civil servants and occasionally guest writers. David Miliband, the current UK Foreign Secretary, began blogging while a minister at the Department of the Environment. Miliband's blog, as well as Jim Murphy's (Minister for Europe), concentrate on policy and their roles as ministers. ${ }^{8}$ Not only does this shed light on the civil service, it also allows the public to interact with what are usually anonymous officials. The entries rarely receive large numbers of comments, though they are read by many. 79 But the advantage of the blog format is that comments and interaction are not pivotal to the experience: many blogs have no comments but this seems to be generally accepted as part of the blogging ecosystem and seemingly does not deter their authors. The general sense of an

7 UK Foreign Office, "FCO Bloggers, Global Conversations," http://blogs.fco.gov.uk (accessed February 14, 2009).

${ }^{78}$ See "David Miliband," https://blogs.fco.gov.uk/roller/miliband (accessed October 15, 2008).

79 Hansard Society, “Digital Dialogues Second Phase Report August 2006-August 2007," http://www.hansardsociety.org.uk/blogs/downloads/default.aspx (accessed October 15, 2008) (London: Hansard Society, 2007). 
ongoing flow of material in a conversational style also avoids the perception that this is a high-stakes, tightly managed environment. The amount of time and staff resources required to run a group blog are also fewer than those required to run a deliberative forum.

Jack Kingston is a Republican Congressman for the First District of Georgia. Kingston encourages constituents to upload questions to YouTube and send him the link via his website. He then responds via YouTube. Kingston also leaves the comment board open on his videos and streams, and they can be rated by users. Kingston's personal website has an excellent blog, which has a fully open comment policy. ${ }^{80}$

The theme may be extended to cover the presentation of politicians' and officials' online personae. Politicians' blogs and YouTube videos tend to avoid jargon and formal stump speech and press release genres. The "microblogging" services such as Twitter, which permits individual messages only 140 characters long, take this informality to extremes. Yet some politicians seem to have adopted it with relish. Stuart Bruce, one-time Director of Communications in the UK Department of Health, said of his minister Alan Johnson: "Using Twitter clearly shows that he's an ordinary guy." 81 In Australia, the state of Victoria's Public Service Continuous Improvement Network describes itself as a "whole of government network" that "includes 2601 members across the Victorian Public Sector." The network's website takes the form of an open comment blog with regular postings by staff. Discussion mostly centers upon ideas related to public service delivery and organizational change but is conducted in a highly informal style. ${ }^{82}$

A final point here concerns the shift away from the open Internet towards the more enclosed environments characteristic of social networking sites. These have been criticized, and there are obvious privacy pitfalls. However, from the perspective of government, the inauthenticity of online discourse has long been a significant hurdle to online consultation. Some of the online mechanisms of web 2.0 are designed to encourage greater trust through a variety of means: use of real names, continuous presence, clear archives, inclusion of photos,

\footnotetext{
80 “Jack Kingston's Blog," http://kingston.house.gov/blog/ (accessed October 15, 2008); and "Jack Kingston's MailTube," http://www.youtube.com/user/JackKingston/ (accessed October 15, 2008).

${ }^{8_{1}}$ Linda Jones, "Member of the Twittering Classes," The Guardian, May 17, 2007.

${ }^{82}$ See "VPSCIN," http://www.vpscin.org (accessed October 15, 2008).
} 
address details, and so on. These provide for a richer, though still admittedly thin, representation of a citizen's "real life" identity. Interactions among citizens in these enclosed environments are a long way from the free-wheeling libertarian ethos of USENET-much admired by the early e-democracy movement-but they do reduce the risk of politically embarrassing comments; they also offer public servants a greater sense of control over the terms of engagement.

\section{B. LESS INDEGREe CENTRALITY, MORE OUTDEGREE CENTRALITY}

Emerging work in e-government ${ }^{83}$ explores the concept of "nodality," described in basic terms by Hood and Margetts as "the property of being in the middle of an information or social network." 84 In quantitative social network analysis, the more common concept is "centrality," which can be defined and measured in a number of ways. The most basic of these is "degree centrality," which refers to the number of links a node has to others. Those with more links to others are in a more "central" position in an information network. However, a further measure of network centrality illustrates the importance of the direction of information flows. "Indegree centrality" refers to the number of incoming links to a node, while "outdegree centrality" refers to the number of outgoing links. Websites with high indegree centrality are more "popular" than those with low indegree centrality, while sites with high outdegree centrality are better at situating themselves within a wider network of sites. Both of these measures of centrality ${ }^{85}$ are relevant for empirically assessing the extent to which a website enjoys an "influential" position.

We can hypothesize that many government departments and agencies will naturally aspire to high indegree centrality because they wish to be authoritative. The evidence that they achieve this is mixed, with reports of low take-up rates for some e-government services,

\footnotetext{
${ }^{83}$ Tobias Escher and others, "Governing from the Centre? Comparing the Nodality of Digital Governments." (lecture, Annual Meeting of the American Political Science Association, August 31, 2006).

${ }_{44}$ Christopher C. Hood and Helen Z. Margetts, The Tools of Government in the Digital Age (New York: MacMillan, 2007), 5.

${ }_{85}$ Alongside others not considered here, see Stanley Wasserman and Katherine Faust, Social Network Analysis: Methods and Applications (Cambridge: Cambridge University Press, 1994): 169-219.
} 
information sites, and, of course, e-democracy sites. ${ }^{86}$ However, we may assume that it is also in a government department's interest to score highly in terms of outdegree centrality. This gives a stronger impression that policymaking is pluralistic and inclusive because the department considers a wide range of organizations and information sources to be worthy of a link. Again, the evidence we have for this surprisingly under-researched phenomenon reveals a low incidence of linking to outside organizations in general ${ }^{87}$ and much variability across government agencies. ${ }^{88}$

The UK Sustainable Development Commission's website has a range of interactive features. It allows users to submit case studies, which can then be rated by those viewing them. There are online calendars, email lists, and basic user profiles with photos and real names. The forum is successful (one thread on housing in February 2008, for example, had 180 comments on it) and is frequently updated. Several sections of the site are behind a registration wall. ${ }^{89}$

For government, strengthening linkages with external organizations allows it to take advantage of the huge reservoirs of material created by the informational exuberance of countless citizens. The recent Power of Information Report produced for the UK Cabinet Office takes this as its central theme, arguing for "experimental partnerships between major departments and user generated sites in key policy areas."90 Similar ideas are at play in the work of companies such as the online market research body Neighborhood America. There is much scope for distributing government sources of information among these online communities, but more importantly, there are opportunities for government to learn

\footnotetext{
${ }^{86}$ UK National Audit Office, "Government on the Internet: Progress in Delivering Information and Services Online," http://www.nao.org.uk/publications/nao_reports/o607/0607529.pdf (accessed October 10, 2008).

${ }^{87}$ Andrew Chadwick and Christopher May, "Interaction between States and Citizens in the Age of the Internet: "E-Government' in the United States, Britain and the European Union." (Paper read at American Political Science Association Annual Meeting, August 30, 2001).

${ }^{88}$ Escher and others, "Governing from the Centre?," 16 (see n. 83).

${ }^{89}$ See "Your say: Sustainable Development Commission," http://www.sdcommission.org.uk/pages/your_say.html (accessed October 15, 2008).

go Ed Mayo and Tom Steinberg, "The Power of Information: An Independent Review," Commentonthis.com, 5, http://www.commentonthis.com/powerofinformation (accessed October 15, 2008).
} 
from the many thousands of daily interactions. Most of these interactions are low threshold and take place on sites such as Netmums, the popular parenting and health advice community with 275,000 users ${ }^{91}$ or TheStudentRoom, with its forums containing upwards of 8 million messages and an 800o-page user generated wiki covering a wide variety of topics related to higher education.92

An initial foray into this new area can be seen in Governmentdocs.org, a project of U.S. civil society organizations including the Sunlight Foundation and the Electronic Frontier Foundation. The site provides an online repository "allowing users to browse, search, and review hundreds of thousands of pages acquired through the Freedom of Information Act (FOIA) and other public disclosure, or 'sunshine,' laws." 93 It encourages "citizen reviewers" to tag, rate and comment on documents. Comments are stored with each document and both are easily linked to and from blogs and other websites. It seems clear that government cannot compete with selforganizing sites in terms of numbers, but it could harness this information to shape policy decisions, and it could tap into these communities to conduct consultations based on the terms of interaction that are the norm for these sites rather than what Whitehall or Washington thinks best.

\section{BEHAVIORAL FEEDBACK}

As discussed above, web 2.0 environments tend to design in outcomes based on aggregated individual behavior. A record of the interactions in these environments - the simple posting of a one line message or the tagging of a video-is information that can be used to sell advertising space or to refine a service. In this way the data become valuable commodities in themselves. The basic informational value of citizens' feedback on government sites is and should be seen as an important component of e-democracy, even though it does not conform to the deliberative ideal. While feedback may take the familiar form of completing web questionnaires and so on, it is also the case that data on the ways in which citizens navigate around sites and the information they perceive as most valuable, measured by the

91 Ibid.

${ }^{22}$ See "The Student Room," http://www.thestudentroom.co.uk (accessed October 15, 2008).

93 See "Governmentdocs," http://www.governmentdocs.org (accessed October 15, 2008). 
time they spend, the clicks they perform, and the documents they download, can be used to shape the design and delivery of services. 94 Textual data in deliberative forums are valuable but labor-intensive to analyze in large quantities. Data from small-scale interactions such as ratings and polls are more amenable to statistical analysis. All of this predates web 2.0, but web 2.0 extends the principle through a more obvious emphasis on aggregating information based on user behavior rather than substantive textual commentary.

\section{CONCLUSION}

Where does this leave e-democracy research? While the study of online deliberative forums will (and should) certainly continue, I suggest that these must be joined by analyses of the phenomena outlined in this paper. We need means, both empirical and normative, of deciding upon the democratic value of forms of engagement that citizens clearly take seriously as part of their repertoire of political expression. In the remainder of this conclusion, I briefly set out two broad sets of issues that are particularly important for such a project.

First, there is the question of the distribution of political power. Granular online engagement implies a diffusion of power, though this is a matter for empirical exploration and it requires rethinking a range of firmly embedded assumptions about representation and the role of intermediaries in liberal democratic political practice. As I argued earlier in this paper, unseating the deliberative assumption does not require that we also unseat the assumption of a politically-motivated citizenry. Schudson 95 has argued for the concept of the "monitorial citizen," understood as one constantly aware of the need to keep a watchful eye on politics but generally content to allow leaders of intermediary institutions-the professional media, parties, and voluntary associations-to play the most important role. As Perez's paper (within this same volume) shows, this influential view has found allies in a range of empirical literature on citizens' cognitive limitations, in which the importance of intermediary groups is seen as paramount for democratic stability. ${ }^{96}$

\footnotetext{
94 Chadwick, "Bringing E-Democracy Back In," 452 (see n. 35).

95 Michael Schudson, The Good Citizen: A History of American Civic Life (New York: The Free Press, 1999), 310-11.

96 Doris Graber, "Mediated Politics and Citizenship in the Twenty-First Century," Annual Review of Psychology 55 (2004): 545-71.
} 
At first glance, it would seem that the sociotechnical environments described above form a perfect habitat for the monitorial citizen, particularly in their low threshold incarnations. But in the era of web 2.0 politics are intermediaries actually as important as Schudson suggests? While there will always be a need to organize, aggregate, filter, and channel, web 2.0 has demonstrated, albeit tentatively so far, that these functions may be distributed among networks, as well as concentrated in formalized leaderships. This leads to a range of questions, both normative and empirical: will the number of intermediaries radically increase, diversify and become more evenly distributed? Will the aggregate sociotechnical environments created by the informational exuberance of citizens continue to multiply, rendering intermediaries less important overall? If political representatives are expected to immerse themselves in these environments, what does this mean for the legitimacy of decisionmaking processes? How can we balance the well-meaning informational exuberance of political "amateurs" against the "expertise" of professional journalists, elected and unelected public servants? Are such categories as meaningful as they once were, now that online co-production is becoming embedded in political life? In short: who governs, and who ought to govern?

The second set of questions relates to a long standing problem of e-democratic practice and it is one that is now potentially an even greater challenge: how can we provide mechanisms that connect the granular information environments of web 2.0 citizen activity with "real" policy-making. My aim in this paper has been to illustrate conceptual points with examples of where this connection is indeed being made, but these constitute just a small part of a much larger universe of political activity, and they are far from perfect. The central questions here are: can the spirit of public experimentalism lead to sustained patterns of interaction between citizens and those who govern, or is it likely to supply government with a new set of excuses for prematurely ending initiatives? Can we in fact escape the one-sizefits-all mentality of deliberative forums? To what extent, and under what conditions are policymakers likely to be incentivized to engage with the third places of online social networks, and, just as importantly, to what extent and under what conditions will citizens be incentivized to welcome policymakers? Do these new environments actually encourage voice and loyalty, while discouraging exit?

No doubt there are many, many other questions that could be raised. This paper has attempted to interpret some of the ways in which recent changes in the online environment present challenges to the dominant assumptions of e-democracy practice and research. It would, of course, be a mistake to suggest that everything web 2.0 is 
new: there are important continuities with earlier phases of online politics. But at the same time, it would also be a mistake to lose sight of the real shifts, both quantitative and qualitative, that the present era heralds for the evolution of democracy. 
